\title{
Ronald Dworkin, Religion without God
}

Cambridge, Massachusetts, and London, England, Harvard University Press, 2012, $180 \mathrm{p}$.

Jean-Louis Ormières

\section{(2) OpenEdition}

1 Journals

\section{Édition électronique}

URL : http://journals.openedition.org/assr/25470

DOI : $10.4000 /$ assr. 25470

ISSN : $1777-5825$

Éditeur

Éditions de l'EHESS

\section{Édition imprimée}

Date de publication : 30 décembre 2013

Pagination : 188

ISSN : 0335-5985

\section{Référence électronique}

Jean-Louis Ormières, «Ronald Dworkin, Religion without God», Archives de sciences sociales des religions [En ligne], 164 | 2013, mis en ligne le 21 février 2014, consulté le 21 septembre 2020. URL: http://journals.openedition.org/assr/25470 ; DOI : https://doi.org/10.4000/assr.25470

Ce document a été généré automatiquement le 21 septembre 2020.

(C) Archives de sciences sociales des religions 


\section{Ronald Dworkin, Religion without God}

Cambridge, Massachusetts, and London, England, Harvard University Press, 2012, $180 \mathrm{p}$.

Jean-Louis Ormières

\section{RÉFÉRENCE}

Ronald Dworkin, Religion without God, Cambridge, Massachusetts, and London, England, Harvard University Press, 2012, 180 p. 
Décédé peu avant la publication de ce petit livre au titre quelque peu paradoxal, mais au contenu fort stimulant, Ronald Dworkin, philosophe américain de premier plan remarqué pour ses importants travaux sur la théorie du droit dans le sillage d'Isaiah Berlin avant de se consacrer à la philosophie politique et d'élaborer une théorie libérale de l'égalité, nous livre ici, en trois chapitres, ses réflexions sur la religion et la présence ou l'absence de Dieu dans la religion.

Dans son premier chapitre, intitulé "Athéisme religieux?», l'auteur, s'appuyant sur les déclarations ou citations diverses de personnalités célèbres connues pour leur athéisme tels qu'Albert Einstein, le poète shelley ou le philosophe William James, invite le lecteur à ne pas se satisfaire d'une opposition qu'il juge trop simpliste, trop caricaturale, entre personnes de religion et personnes sans religion. Si tous ces illustres personnages affirment ne pas croire en un Dieu « personnel », ils croient néanmoins en une «force » dans l'univers « plus grand que nous ne sommes ».

3 R. Dworkin remarque dès lors que croyants et non-croyants partagent un sentiment d'émerveillement. Ne ressentent-ils pas la même sensation à la vue d'une nature aussi grandiose et saisissante que le Grand Canyon ? N'éprouvent-ils pas la même angoisse en observant un ciel étoilé face à l'étendue de l'univers? Einstein tout en se disant athée se considérait comme un homme profondément religieux, préférant adopter une attitude d'humilité correspondant à la faiblesse de notre compréhension intellectuelle de la nature et de notre propre être.

e même que l'on croit en un Dieu personnel ou que l'on soit un agnostique, nous nous soucions les uns et les autres de vivre en accord avec nos valeurs morales et en traitant les autres avec décence.

Dans le second chapitre (L'Univers), l'auteur examine les différentes valeurs religieuses de la beauté céleste qui ont influencé Albert Einstein et nombre de ses collègues. Pour les théistes, l'auteur de cette beauté ne peut qu'être un Dieu: seul un Dieu a pu délibérément créer ce site spectaculaire qu'est le Grand Canyon. Mais un athée, tout en étant aussi sensible à ce site considère qu'il est le fruit d'un processus évolutionnaire global qui lui confère une émotion particulière.

6 Deux questions dominent ce chapitre, d'une part, quel est le rôle que la foi en la beauté objective de l'univers joue dans la recherche et la spéculation réelle de tout physicien? Pour la plupart des physiciens aujourd'hui l'univers incarne vraiment une beauté sublime qui ne suppose nullement qu'un Dieu soit à l'origine de cette beauté. Pour Dworkin, c'est là l'exemple d'un "athéisme religieux" (bien que nombre de ces physiciens refuseraient, souligne-t-il, cette appellation). Autrement dit, la beauté 
basique qu'espèrent vraiment trouver les physiciens serait assimilable à une puissante et profonde démonstration mathématique.

7 Les théismes insistent sur le fait que si Dieu explique tout, sa propre existence n'a pas besoin d'être expliquée car il existe nécessairement. Les athées religieux comme Einstein ont, nous dit l'auteur, une foi parallèle. Ils rêvent d'une nouvelle sorte de nécessité : la nécessité cosmique.

8 Le troisième chapitre traite de la liberté religieuse. Aujourd'hui, la liberté de pensée et de conscience est inscrite dans la plupart des constitutions des pays démocratiques et dans les grands traités internationaux. La liberté d'expression s'applique à toutes les religions comme à ceux qui sont athées. Cela n'a pas toujours été le cas comme le rappelle l'auteur. John Locke, l'un des premiers à s'être prononcé en faveur de la liberté religieuse, n'en avait-il pas exclu les athées estimant que l'on ne pouvait leur accorder des droits de citoyen.

9 Pour s'assurer que tout individu a le droit au libre exercice de ses convictions, qu'elles impliquent la croyance en un Dieu ou non, il semble qu'il faille redéfinir ce qu'est une attitude religieuse et avant tout opérer une séparation entre religion et Dieu. Mais cela peut-il suffire? Rappelant que la liberté religieuse exigeant du gouvernement qu'il n'exerce aucune discrimination à l'encontre d'une quelconque religion, la Native American Church ne put être poursuivie pour l'utilisation du peyotl, un hallucinogène, dans ses rituels religieux. Dès lors, si la loi reconnait les religions sans Dieu, mais en exclut tous ceux qui pensent que l'usage des substances hallucinogènes est indispensable à leur approche de la vie, elle opère une discrimination sur une base religieuse à l'encontre de ceux qui veulent se «droguer». On le voit, la question est complexe.

Dworkin achève ce chapitre avec un espoir ou plutôt, le mot est de circonstance, « une prière ». Ayant tout au long de ce court essai tenté de montrer que tous les peuples partagent un élan religieux fondamental qui se manifeste en émotions et convictions diverses et que cet élan a généré deux sortes de convictions fondamentales, une croyance en une force surnaturelle - un Dieu - et un ensemble de convictions éthiques et morales profondes, il ne désespère pas que théistes et athées parviennent à accepter que ce qu'ils prennent pour un fossé infranchissable est seulement "une sorte ésotérique de désaccord scientifique sans implication morale ou politique.» Richard Dworkin ne cache pas néanmoins un scepticisme certain: «Est-ce trop espérer? Probablement » conclut-il.

11 Pour finir, s'interrogeant sur la mort, l'auteur affirme que chacun d'entre nous, qu'il soit déistes ou athée l'affronte en croyant avoir fait quelque chose de bien en réponse au plus grand challenge auquel tout mortel doit faire face. 